\title{
Источники кимберлитоподобных пород и ультрамафических лампродиров в Восточном Присаянье по изотопно- геохимическим данным
}

Данилова Ю.В., Савельева В.Б., Демонтерова Е.И., Базарова Е.П., Данилов Б.С. Институт земной коры СО РАН, Иркутск, jdan@сrust.irk.ru

Аннотация. На основании данных об особенностях химического состава и изотопных характеристиках Sm и $\mathrm{Nd}$ сделан вывод о предполагаемом источнике расплава, ответственного за формирование дайково-жильных кимберлитоподобных пород и ультрамафических лампрофиров зиминского щелочноультраосновного комплекса в Восточном Присаянье.

Ключевые слова: кимберлит, кимберлитоподобные породы, щелочно-ультраосновной комплекс, источники расплавов.

\section{The sources of the melt of kimberlite-like rocks and ultramafic lamprophyres in the Eastern Sayan area according to isotope- geochemical data}

\author{
Danilova Yu.V., Savel'eva V.B., Demonterova E.I., Bazarova E.P., Danilov B.S. \\ Institute of the Earth's Crust, SB RAS, Irkutsk,128 Lermontov St, jdan@crust.irk.ru
}

\begin{abstract}
A conclusion was made about the supposed source for the formation of dyke-vein kimberlite-like rocks and ultramafic lamprophyres of the Zima alkaline-ultramafic complex in the Eastern Sayan area on the basis of data on the chemical composition and isotopic characteristics of $\mathrm{Sm}$ and $\mathrm{Nd}$.
\end{abstract}

Key words: kimberlite, kimberlite-like rocks, alkaline-ultrabasic complex, sources of melts.

\section{Введение}

В конце позднего рифея в пределах Урикско-Ийского грабена формировались крупные щелочно-карбонатитовые массивы. В этом же временном интервале происходило внедрение роев даекщелочно-ультраосновного состава. Возраст внедрения, ориентировочно составляет 600 млн. лет., что близко к датированным карбонатитам Белозиминского массива - 543 млн лет, K-Ar метод по (Багдасаров и др., 1980) и 645 млн. лет, Ar-Ar метод по (Doroshkevich et al., 2016). Возраст нефелиновых сиенитов Белозиминского массива по результатам датирования циркона $\mathrm{U}-\mathrm{Pb}$ методом (Yarmolyuk et al., 2005) составляет $643 \pm 4$ млн. лет. В данной работе исходя из минералогогеохимических и изотопных $\mathrm{Sm}$ и $\mathrm{Nd}$ характеристик выдвинуто предположение об источнике расплава, ответственного за формирование даек и жил кимберлитоподобных пород и ультрамафических лампрофиров.

\section{Геология района}

Согласно (Багдасаров и др., 2001) массивы щелочно-ультраосновных пород и карбонатитов Урикско-Ийского грабена в Восточном Присаяньи объединены в зиминский комплекс. Комплекс состоит из Белозиминского, Большетагнинского, Среднезиминского щелочно-карбонатитовых массивов, с ними сопряжена Ярминская интрузивная (дайково-жильная) зона (рис. 1). Большетагнинский карбонатитовый массив с ультраосновными щелочными породами расположен в 10 км к северо-западу от более известного Белозиминского карбонатитового массива, в водораздельной части рек Белая Тагна и Ярма, притока реки Большого Кирея (Иркутская область, Тулунский район). Ярминская дайково-жильная зона располагается на 9-12 км юго-западнее Большетагнинского массива, в правом борту реки Ярма и ее притоков. Карбонатитовые массивы сопровождаются интракратонными и развитыми за пределами массивов сериями даек и жил щелочно-ультраосновного состава. Среди сходных на первый взгляд по минеральному составу пород ультраосновного щелочного состава выделяются жилы и дайки мощностью от первых десятков сантиметров до несколь- 


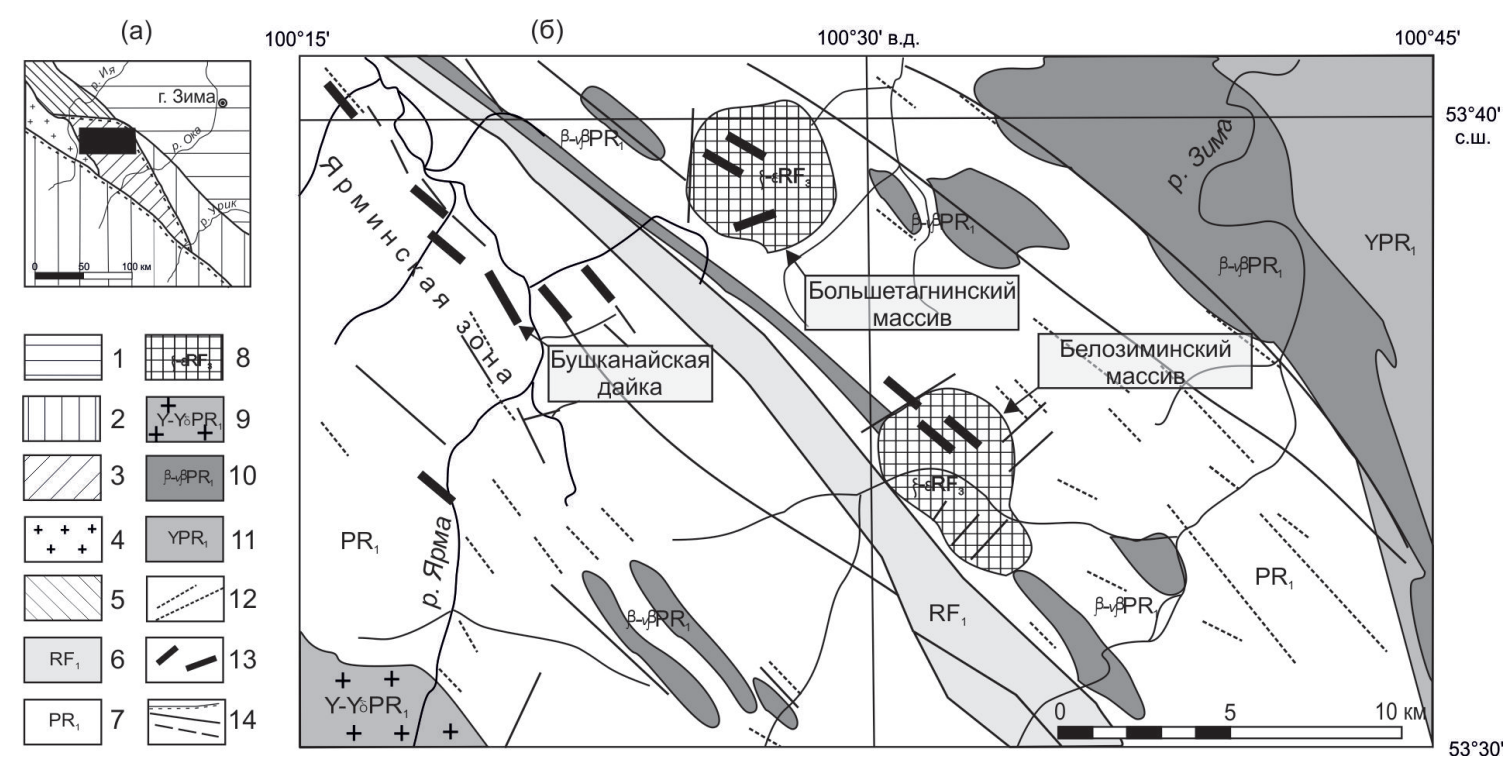

Рис. 1. Схемы расположения зиминского комплекса в пределах Урикско-Ийского грабена (а) и геологического строения участка работ (б).

(a): 1 - фанерозойский осадочный чехол; 2 - раннедокембрийские гранитогнейсовые комплексы; 3 - УрикскоИйский грабен $\mathrm{PR}_{1} ; 4$ - граниты $\mathrm{PR}_{1} ; 5$ - отложения Присаянского прогиба $\left(\mathrm{RF}_{3}-\mathrm{V}\right)$. (б): 6 - терригенные отложения $\mathrm{RF}_{1} ; 7$ - вулканогенно-осадочные отложения $\mathrm{PR}_{1} ; 8$ - зиминский комплекс ультраосновных щелочных пород и карбонатитов $\mathrm{RF}_{3} ; 9$ - граниты саянского комплекса $\mathrm{PR}_{1} ; 10$ - габбро-диабазы $\mathrm{PR}_{1} ; 11$ - гнейсограниты $\mathrm{PR}_{1} ; 12$-жилы основного состава нерасчлененные; 13 - дайки и жилы ультраосновного щелочного состава (вне масштаба); 14 - разломы.

Fig. 1. Schematic maps showing the locations of the Zima complex in the Urik-Iya graben (a) and the geological structure of the study area (б).

(a): 1 - Phanerozoic sedimentary cover; 2 - Early Precambrian granite-gneiss complexes; 3 - Urik-Iya graben $\mathrm{PR}_{1}$; 4 - granite $\mathrm{PR}_{1} ; 5$ - deposits of the Sayan trough $\left(\mathrm{RF}_{3}-\mathrm{V}\right)$. (б): 6 - terrigenous deposits $\mathrm{RF}_{1} ; 7$ - volcanic-sedimentary deposits $\mathrm{PR}_{1} ; 8$ - Zima complex of ultrabasic-alkaline rocks and carbonatite $\mathrm{RF}_{3} ; 9$ - granite of the Sayan complex $\mathrm{PR}_{1} ; 10$ - gabbro diabase $\mathrm{PR}_{1} ; 11$ - gneiss-granite $\mathrm{PR}_{1} ; 12$ - non-segmented veins of the main composition; 13 - dikes and veins of the ultrabasic alkaline composition (out of scale); 14 - faults.

ких метров флогопит-пироксеновых, беспироксеновых щелочных пикритов и ультрамафических лампрофиров (Petrographic Code ..., 2008; Tappe et al., 2005). Жилы Ярминской зоны представлены ультрамафическими лампрофирами (айлликиты, дамтьерниты) и Бушканайской дайкой, сложенной слюдистыми щелочными пикритами с кимберлитом. Жилы беспироксеновых пикритов обнаружены только в Большетагнинском массиве.

\section{Петрохимический состав пород}

Айлликиты имеют порфировидную структуру с тонко- и мелкозернистой основной массой, которая состоит из флогопита, кальцита, диопсида, серпентина, талька, доломита. Вкрапленники образованы оливином и флогопитом. Свежий оливин встречается редко, в большинстве случаев замещен серпентином, магнетитом, тальком, доломитом, редко кальцитом. Акцессорные минералы представлены хромшпинелидами, титаномагнетитом, перовскитом, манганильменитом, рутилом, апатитом, гранатом.

Отдельные жилы по сравнению с вышеописанными породами заметно обеднены оливином и обогащены слюдой. Основная масса сложена клинопироксеном, флогопитом, керсутитом, в подчиненном количестве присутствуют калиевый полевой шпат, альбит, титаномагнетит, манганильменит, перовскит, апатит, серпентин, тальк, хлорит. Слюда присутствует во вкрапленниках и в основной массе. Порфировидные выделения оливина, нацело замещены серпентином, тальком и доломитом. По классификации (Tappe et al., 2005) породы можно отнести к дамтьернитам, как породам, содержащим щелочной полевой шпат. 
Флогопит-пироксеновый пикрит представляет собой мезократовую породу с порфировидной структурой. Основная масса состоит из серпентина, флогопита, клинопироксена, хлорита, гидрограната, тремолита, кальцита, шпинелидов. Вкрапленники образованы серпентинизированным оливином и флогопитом. Содержания клинопироксена и слюды в образцах сильно варьируют.

Пикрит содержит включения меланократовой неравномернозернистой породы, на 65-70 \% сложенной зернами серпентинизированого оливина и редкими зернами хромдиопсида. Основная масса образована серпентином, серпентинизированным оливином, хлоритизированным флогопитом, гидрогранатом, кальцитом, шпинелидами, апатитом. По минеральному составу порода близка к кимберлиту (Минаева, Егоров, 2008).

В Большетагнинском ийолит-сиенит-карбонатитовом массиве распространены дайки беспироксеновых щелочных пикритов. Основная масса состоит из серпентина, кальцита, флогопита, монтичеллита, хлорита, талька, титанистого граната, шпинелидов, апатита, перовскита, гидрограната. Вкрапленники представлены главным образом зернами серпентинизированного оливина, в отдельных жилах присутствуют вкрапленники флогопита.

В целом породы характеризуются очень низким содержанием $\mathrm{SiO}_{2}, \mathrm{Al}_{2} \mathrm{O}_{3}$, сильно варьирующим содержанием $\mathrm{MgO}, \mathrm{CaO}, \mathrm{CO}_{2}, \mathrm{TiO}_{2}$ и $\mathrm{Na}_{2} \mathrm{O}$. На бинарных диаграммах составы изученных пород частично перекрываются и попадают в поля составов кимберлитов Амона и ультрамафических лампрофиров Торнгата и Саглека в Северной Америке (Тappe, 2008; Тарре, 2014). Точки составов пикрита и кимберлита Бушканайской дайки и беспироксеновых пикритов Большетагнинского массива, на диаграммах (рис. 2 а-г) (Becker et al., 2007) попадают в поле кимберлитов. Образец кимберлита Бушканайской дайки является самым низкотитанистым и низкокалиевым. Точка его состава располагается в области перекрытия полей южно-африканских кимберлитов I и II групп (Becker, le Roex, 2006). Для него характерны также низкие содержания $\mathrm{SiO}_{2}, \mathrm{Al}_{2} \mathrm{O}_{3}, \mathrm{TiO}_{2}, \mathrm{CaO}, \mathrm{K}_{2} \mathrm{O}$ и $\mathrm{Na}_{2} \mathrm{O}$ при резком преобладании $\mathrm{K}$ над $\mathrm{Na}$ и умеренные содержания $\mathrm{FeO}_{\text {общ, }} \mathrm{CO}_{2}$. Кимберлит Бушканайской дайки характеризуется также высокими концентрациями $\mathrm{Ni}, \mathrm{Co}, \mathrm{Cr}$, но низкими $\mathrm{V}, \mathrm{Cu}, \mathrm{Rb}, \mathrm{Ba}, \mathrm{Sr}$, высокозарядных и легких редкоземельных элементов (рис. 2 е). Индекс контаминации СI составляет всего 1.1 и позволяет предположить, что кимберлит Бушканайской дайки не претерпел существенного загрязнения коровым материалом. Пикриты, слагающие Бушканайскую дайку, имеют высокий индекс загрязнения $\mathrm{CI}=2.0$ и характеризуются повышенным содержанием $\mathrm{Al}_{2} \mathrm{O}_{3}, \mathrm{TiO}_{2}$, $\mathrm{CaO}, \mathrm{K}_{2} \mathrm{O}, \mathrm{Na}_{2} \mathrm{O}, \mathrm{P}_{2} \mathrm{O}_{5}, \mathrm{Fe}_{2} \mathrm{O}_{3}$.

Айлликиты и дамтьерниты, в общем, содержат больше $\mathrm{TiO}_{2}, \mathrm{~K}_{2} \mathrm{O}, \mathrm{CO}_{2}$ и меньше $\mathrm{MgO}$ по сравнению с беспироксеновыми пикритами. СаО беспироксеновых пикритов входит в состав первичномагматического кальцита и постмагматического доломита (рис. 2 д). Точки составов айлликитов находятся в поле ультрамафических лампрофиров, тогда как дамтьерниты с крайне низким содержанием $\mathrm{MgO}$ на диаграмме (рис. 2 в) располагаются вне полей кимберлитов и ультрамафических лампрофиров. $\mathrm{B}$ дамтьернитах повышено содержание $\mathrm{TiO}_{2}, \mathrm{Al}_{2} \mathrm{O}_{3}, \mathrm{FeO}_{\text {общ }}, \mathrm{P}_{2} \mathrm{O}_{5}, \mathrm{~K}_{2} \mathrm{O}$ и $\mathrm{Na}_{2} \mathrm{O}$ и самый высокий индекс СI (2.8) (Индекс контаминации $\mathrm{CI}=\left(\mathrm{SiO}_{2}+\mathrm{Al}_{2} \mathrm{O}_{3}+\mathrm{Na}_{2} \mathrm{O}\right) /\left(\mathrm{MgO}+2 \mathrm{~K}_{2} \mathrm{O}\right)$ (Clement, 1982), тогда как в айлликитах СІ от 1.3 до 2.1. Это позволяет предположить, что большинство ультрамафических лампрофиров претерпело значительную контаминацию коровым материалом. В ультрамафических лампрофирах несколько понижено содержание $\mathrm{Ni}, \mathrm{Co}, \mathrm{Cr}$, при более высоком $\mathrm{Zr}, \mathrm{Nb}, \mathrm{Ba}$ и LREE по сравнению с кимберлитом. На диаграммах $\mathrm{Ce}-\mathrm{Nb}, \mathrm{Ce} / \mathrm{Y}-\mathrm{Nb} / \mathrm{Zr}$, ультрамафические лампрофиры демонстрируют сходство с кимберлитом и пикритами Бушканайской дайки, образуя общее облако точек. На диаграмме $\mathrm{Ba} / \mathrm{Nb}-\mathrm{La} / \mathrm{Nb}$ эти же образцы, напротив, показывают большой разброс значений, часть из которых сходны по микроэлементному составу с кимберлитами I группы, а дамтьерниты приближаются к кимберлитам II группы (оранжеитам по (Becker, le Roex, 2006)).

Беспироксеновые пикриты Большетагнинского массива имеют низкое содержание $\mathrm{SiO}_{2}, \mathrm{Al}_{2} \mathrm{O}_{3}$, умеренно высокое $\mathrm{TiO}_{2}, \mathrm{~K}_{2} \mathrm{O}$, варьирующееся $\mathrm{MgO}$. Содержание $\mathrm{Na}_{2} \mathrm{O}$ в беспироксеновых пикритах низкое, а отношение $\mathrm{K}_{2} \mathrm{O} / \mathrm{Na}_{2} \mathrm{O}$ выше, чем в кимберлите. Индекс СІ колеблется от низкого 1.2 до высокого 1.9 (в сильно хлоритизированных образцах). На диаграммах (рис. 2 е-з) они отчетливо обособляются как от ультрамафических лампрофиров, так и пикритов и кимберлита Бушканайской дайки. 

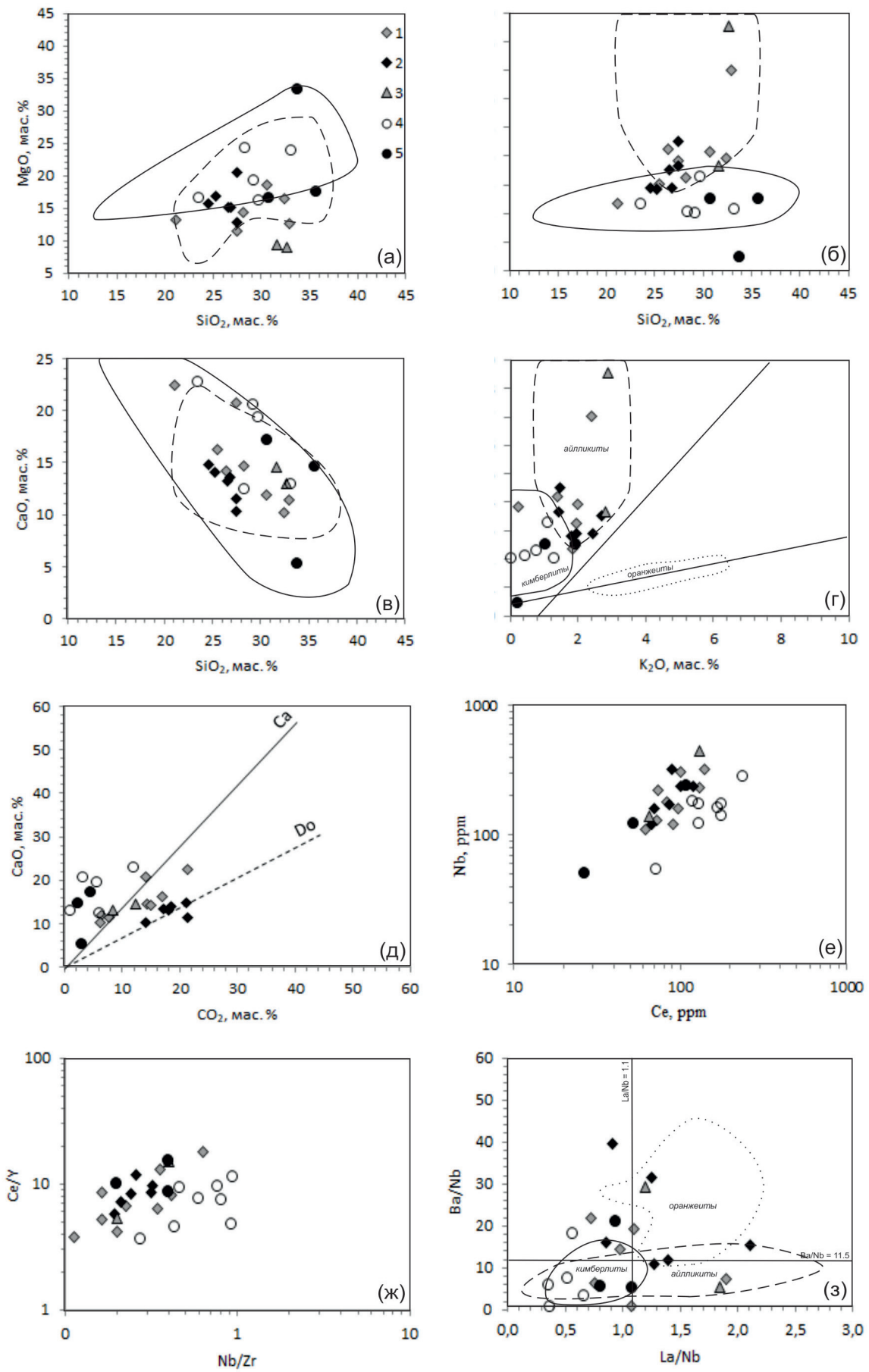

Рис. 2. Вариации петрогенных оксидов и соотношения $\mathrm{Nb}-\mathrm{Ce}, \mathrm{Ce} / \mathrm{Y}-\mathrm{Nb} / \mathrm{Zr}, \mathrm{Ba} / \mathrm{Nb}-\mathrm{La} / \mathrm{Nb}$ в кимберлитоподобных породах и ультрамафических лампрофирах.

На фрагментах: 1 - неизмененные айлликиты; 2 - доломитизированные айлликиты; 3 - дамтьерниты; 4 - беспироксеновые пикриты; 5 - кимберлит и флогопит-пироксеновые пикриты.

Контурными линиями выделены поля: сплошная - кимберлиты I группы, пунктирная - ультрамафические лампрофиры (айлликиты, дамтьерниты), точечная - кимберлиты II группы (оранжеиты).

Fig. 2. Variations major oxides and the ratios of $\mathrm{Nb}-\mathrm{Ce}, \mathrm{Ce} / \mathrm{Y}-\mathrm{Nb} / \mathrm{Zr}, \mathrm{Ba} / \mathrm{Nb}-\mathrm{La} / \mathrm{Nb}$ for kimberlite-like rocks and ultramafic lamprophyres.

On the fragments: 1 - unmodified aillikity; 2 - dolomitized aillikites; 3 - damtiernites; 4 - pyroxene-free picrites; 5 - kimberlite and phlogopite-pyroxene picrites.

The contour lines mark the fields: solid - kimberlites of groups I, dashed - ultramafic lamprophyres (aillikites, damtiernites), dotted - kimberlites of groups I (orangeites). 


\section{Sr-Nd изотопная систематика}

Значения $\varepsilon \mathrm{Sr}$ и $\varepsilon \mathrm{Nd}$ в кимберлите, айлликите, флогопит-пироксеновом и беспироксеновом пикритах составляют соответственно от -10.3 до +66.1 и от +2.4 до +3.9 . Анализы выполнены в ЦКП «Геодинамика и геохронология», ИЗК СО РАН (г. Иркутск). В целом, точки составов пород группируются в линейно вытянутый тренд, параллельный оси $\varepsilon \operatorname{Sr}(\mathrm{T})$ (рис. 3). Отрицательное значение $\varepsilon \mathrm{Sr}$ показывает только образец беспироксенового пикрита Большетагнинского массива. Эта точка с параметрами $\varepsilon \operatorname{Sr}(-10.3)$ и $\varepsilon \mathrm{Nd}(3.9)$ граничит с полями кимберлитов Сибири группы I и скомпилированных данных по кимберлитам Южной Африки и Китая и располагается наиболее близко к источникам типа OIB (Carlson et al., 2006; Smith, 1983; Toyama et al., 2012). Изотопные характеристики образцов пикрита и айлликита из даек Ярминской зоны аналогичные с кимберлитами группы I и попадают в поле кимберлитов Сибири, Южной Африки, Китая. В тоже время единственный среди наших образцов кимберлит не ассоциируется ни с одним из нанесенных для сравнения полей кимберлитов. Концентрация $\varepsilon \mathrm{Sr}$ в кимберлите Бушканайской дайки дает значение +66.1 что соответствует сильно обогащенному изотопному составу. Обогащение радиогенным стронцием связано с изменением $\mathrm{Rb} / \mathrm{Sr}$ отношения под влиянием вторичных процессов в минеральных фазах самого кимберлита.

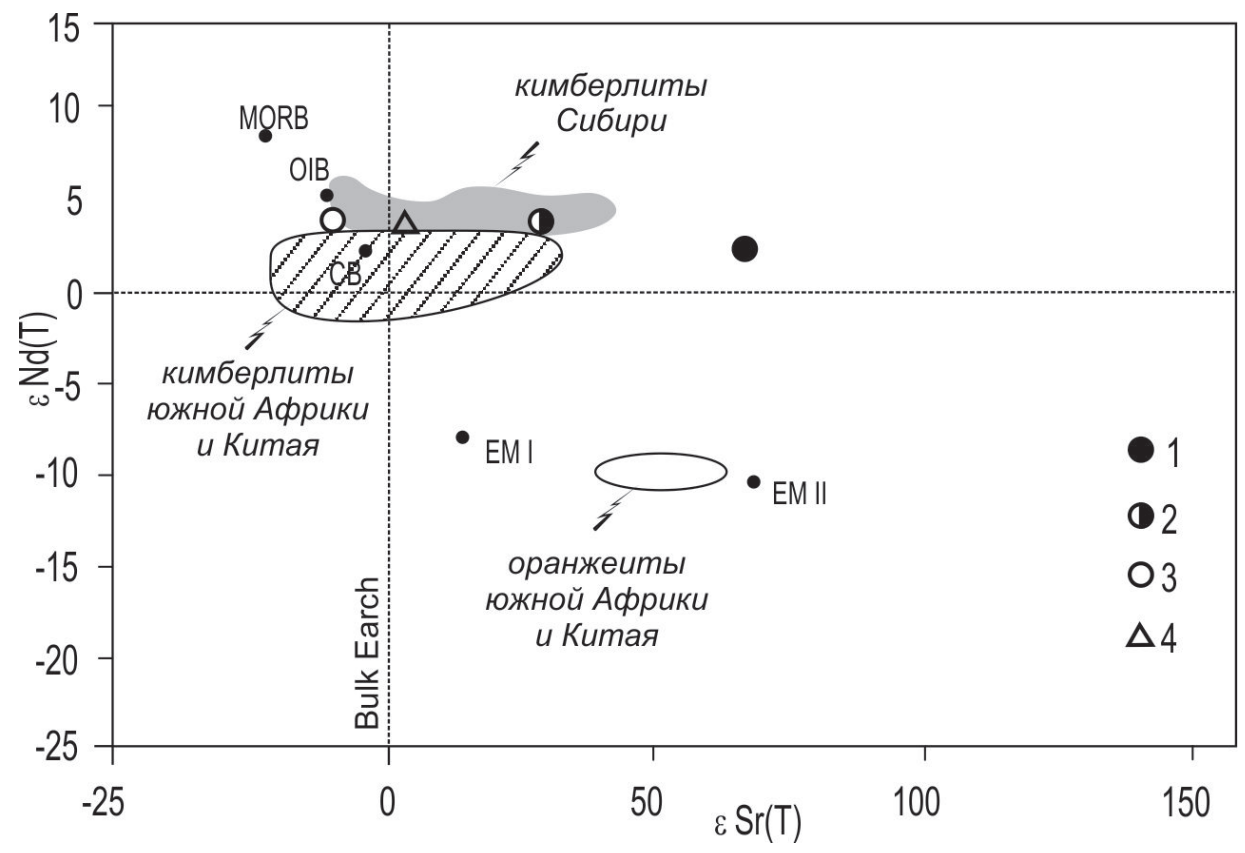

Рис. 3. Диаграмма $\varepsilon \operatorname{Nd}(\mathrm{T})-\varepsilon \operatorname{Sr}(\mathrm{T})$ в кимберлитоподобных породах и ультрамафических лампрофирах.

1 - кимберлит; 2 - флогопит-пироксеновый пикрит; 3 - беспироксеновый пикрит; 4 - айлликит. Для сопоставления нанесены поля составов кимберлитов I и II группы и переходных Южной Африки, Китая и Сибири (Becker, le Roex, 2007; Toyama et al., 2012; Carlson et al., 2006). Изотопные составы континентальных базальтов (CB), серединно-океанических хребтов (MORB), океанических островов (OIB) и обогащенной мантии - ЕM I и ЕМ II взяты из работы (Iwamori, Nakamura 2015).

Fig. 3. $\varepsilon \operatorname{Nd}(\mathrm{T})-\varepsilon \operatorname{Sr}(\mathrm{T})$ diagram for for kimberlite-like rocks and ultramafic lamprophyres.

1 - kimberlite; 2 - phlogopite-pyroxene picrite; 3 - pyroxene-free picrite; 4 - aillikit. For comparison reasons, the diagram also shows the compositional fields of kimberlites of groups I, II and transitional ones of South Africa, China, and Siberia (Becker, le Roex, 2007; Toyama et al., 2012; Carlson et al., 2006). The isotopic compositions of continental basalts (CB), mid-ocean ridges (MORB), basalts in oceanic islands (OIB), and enriched mantle EM I and EM II are from (Iwamori, Nakamura 2015).

\section{Заключение}

$\mathrm{Sr}-\mathrm{Nd}$ изотопная систематика позволяет предполагать существование гетерогенного мантийного источника во время образования дайково-жильных серий кимберлитов. Наблюдаемый на рис. 2 тренд указывает на участие в формировании расплавов деплетированной мантии. В то же время, 
геохимические различия между беспироксеновыми пикритами, флогопит-пироксеновыми пикритами и айлликитами, предполагают участие метасоматизированной мантии, из которой выплавлялись эти породы, в частности, образование айлликитов из источника, обогащенного карбонатами. Кимберлит и пикрит Бушканайской дайки по химическому и микроэлементному составам наиболее близки к кимберлитам Мира. Очень высокое значение $\varepsilon \mathrm{Sr}$ свидетельствует о влиянии вторичных изменений на Rb/Sr систему и является основанием для отнесения кимберлита к области контаминированного источника.

Работа выполнена при частичной финансовой поддержке Интеграционного проекта ИНЦ СО РАН, блок 1.4.

\section{Литература}

1. Багдасаров Ю.А., Вороновский С.Н., Аракелянц М.М. Новые данные К - Ar возраста ультраосновныхщелочных карбонатитовых массивов Восточных Саян и некоторые вопросы их образования // Доклады АН СССР. 1980. Т. 254. № 1. C. 171-175.

2. Багдасаров Ю.А., Гусев Г.С., Гущин А.В., Межеловский Н.В., Морозов А.Ф. Металлогения магматических комплексов внутриплитовых геодинамических обстановок. М. Изд-во: ГЕОС. 2001. 640 с.

3. Минаева Ю.А., Егоров К.Н. Минералого-петрографические особенности дайки кимберлит-пикритового состава в северо-западной части Урикско-Ийского грабена (Восточное Присаянье) // Записки РМО. 2008. № 3. С. 23-39.

4. Петрографический кодекс России. Магматические, метаморфические, метасоматические, импактные образования. СПб. Изд-во: ВСЕГЕИ. 2008. 200 с.

5. Ярмолюк В.В., Коваленко В.И., Сальникова Е.Б., Никифоров А.В., Котов А.Б., Владыкин Н.В. Позднерифейский рифтогенез и распад Лавразии: данные геохронологических исследований ультраосновных щелочных комплексов в южном обрамлении Сибирского кратона // Доклады АН. 2005. Т. 404. № 3. C. 400-406.

6. Becker M., le Roex A. Geochemistry and petrogenesis of South African transitional kimberlites located on and off the Kaapvaal Craton // South African Journal of Geology. 2007. 110 (4). P. 631-646.

7. Becker M., le Roex A.P. Geochemistry of South African on- and off-Craton, Group I and Group II Kimberlites: Petrogenesis and Source Region Evolution // Journal of Petrology. 2006. 47 (4). P. 673-703. http://dx.doi. org/10.1093/petrology/egi089.

8. Carlson R.W., Czamanske G., Fedorenko V., Ilupin I. A comparison of Siberian meimechites and kimberlites: implications for the source of high-Mg alkalic magmas and flood basalts // Geochemistry Geophysics Geosystems. 2006. 7 (11). P. 1525-2027. https://doi.org/10.1029/2006GC001342.

9. Clement C.R. A comparative geological study of some major kimberlite pipes in the Northern Cape and Orange Free State. University of Cape Town. 1982. 432 p.

10. Doroshkevich A.G., Veksler I.V., Izbrodin I.A., Ripp G.S., Khromova E.A., Posokhov V.F., Travin A.V., Vladykin N.V. Stable isotope composition of minerals in the Belaya Zima plutonic complex, Russia: Implications for the sources of the parental magma and metasomatizing fluids // Journal of Asian Earth Sciences. 2016. 116. P. 81-96. https://doi.org/10.1016/j.jseaes.2015.11.011

11. Iwamori H., Nakamura H. Isotopic heterogeneity of oceanic, arc and continental basalts and its implications for mantle dynamics // Gondwana Research. 2015. 27. P. 1131-1152. http://dx.doi.org/10.1016/j.gr.2014.09.003

12. Smith C.B. Pb, Sr and Nd isotopic evidence for sources of southern African Cretaceous kimberlites // Nature. 1983. 304. P. 51-54.

13. Tappe S., Foley S.F., Jenner G.A., Kjarsgaard B.A. Integrating Ultramafic Lamprophyres into the IUGS Classification of Igneous Rocks: Rationale and Implications // Journal of Petrology. 2005. 46 (9), P. 1893-1900. http://dx.doi.org/10. 1093/petrology/egi039.

14. Tappe S., Foley S.F., Kjarsgaard B.A., Romer R.L., Heaman L.M., Stracke A., Jenner G.A. Between carbonatite and lamproite Diamondiferous Torngat ultramafic lamprophyres formed by carbonate-fluxed melting of cratonic MARID-type metasomes // Geochimica et Cosmochimica Acta. 2008.72. P. 3258-3286. http://dx.doi:10.1016/j.gca.2008.03.008.

15. Tappe S., Kjarsgaard B.A., Kurszlaukis S., Nowell G.M., Phillips D. Petrology and Nd-Hf Isotope Geochemistry of the Neoproterozoic Amon Kimberlite Sills, Baffin Island (Canada): Evidence for Deep Mantle Magmatic Activity Linked to Supercontinent Cycles // Journal of Petrology. 2014. 55 (10). P. 2003-2042. http://dx.doi. org/10.1093/petrology/egu048.

16. Toyama C., Muramatsu Ya., Yamamoto J., Nakal S., Kaneoka I. Sr and Nd isotope ratios and trace element concentrations in kimberlites from Shandong and Liaoning (China) and the Kimberley area (South Africa) // Geochemical Journal. 2012. 46. P. 45-59. https://doi.org/10.2343/geochemj.1.0151. 